\title{
La Iglesia de los pobres, concreción latinoamericana del Vaticano II. Ante el próximo sínodo extraordinario
}

\author{
JON SOBRINO \\ Centro de Reflexión Teológica, \\ San Salvador, El Salvador.
}

El sinodo extraordinario de obispos, que se celebrará en Roma a finales de este año, tiene como linalidad la evaluación del concilio Vaticano II o, más exactamente, de las consecuencias que desde él o con ocasión de él se han derivado para la Iglesia. Su convocatoria y, sobre todo, algunas manifestaciones sobre el actual estado de la Iglesia postconciliar, como las conocidas declaraciones del cardenal Ratzinger, han causado sorpresa y en muchos ambientes cierto temor. Y ello no tanto porque no se vea conveniente algún tipo de asamblea general de la Iglesia -recuérdese por ejemplo, que $\mathrm{H}$. Küng pedia hace años la convocatoria de un Vaticano III-, sino porque se teme una marcha atrás como si ya se hubiese alcanzado el máximo conciliar en lo que tiene de novedad y como si lo que tocaria ahora es defender esa novedad de sus exageraciones y desviaciones. K. Rahner pensaba más bien que la novedad del Vaticano II fue tan radical que llevaría un siglo el asimilarla en la generalidad de la Iglesia. Se teme pues que el sínodo ahogue prematuramente al concilio, presuponiendo que sus virtualidades positivas novedosas ya estuviesen agotadas - lo cual no se debe presuponer, sino todo lo contrario-, y que la crítica a las exageraciones y desviaciones suponga la muerte lenta, la muerte de las mil cualificaciones al espiritu y a los contenidos más fundamentales del concilio.

En América Latina este temor se concentra en que se opere una marcha atrás con respecto a Medellin, tarea ya intentada pero sólo con éxito parcial en Puebla; a lo cual se añade el dolor, pues Medellin ha representado el momento más importante de la historia eclesial en América Latina cuando por primera vez la Iglesia se hizo auténticamente evangélica y auténticamente latinoamericana. En Medellin la Iglesia encontró la perla preciosa y el tesoro escondido, se puso a vender todo lo que tenía -y hasta le costó la vida-; pero hallo el gozo de haber encontrado su identidad y relevancia, su lugar en el continente y su misión, su fe y su esperanza. Tal novedad fue experimentada como verdadero don de Dios y, por ello, como lo más intimo y sagrado que hay que conservar y entregar a futuras géneraciones. 
Medellin fue posible por razones intrinsecas lalinoamericanas, pero sin el Valicano II no hubiesc tenido lugar. Lo que el concilio tuvo de acoitecimiento eclesial y lo que tuvo de espiritu y de contenidos fundamentales, fueron necesarios para la realidad de Medellín. No fueron sulicientes desde todo punto de vista, pero sin ellos no hubiera cxistido Medellin. De ahi que una evaluación del concilio es visıa automáticamente en América Latina como una evaluación de Medellin: $y$ de ahi la expectativa $y$ el temor.

En este arliculn glieremos concenırarmos on la realidad de la Iglesia latinoamericana, pero - en presencia del próximo sínodo- en su relación con el Vaticano [1. Queremos mostrar a esta I glesia como concreción del concilio, lo cual significa dos cosas: que el concilio fue importante para la lglesia latinoamericana y que ésla es importantc para conocer también lo que fue el concilio en su espirilu, contenido y virlualidades. Queremos mostrar más en concreto que Medellin, como simbolo de la novedad de la Iglesia latinoamericana, y lo que desencadenó represesta un modelo privilegiado de recepción del concilio por parte de una Iglesia local.

Como hecho empirico, se ha reconocido que Medellin ha sido la aplicación más significativa y novedosa del concilio, aunque en otras partes del mundo también el concilio ha tenido importantes repercusiones. Medellin significó, en efecto, una singular recepción del concilio. Lo recibió irans 「ormándolo, es decir, no como mera aplicación de lo universal a lo concreto, en lo cual lo universal se empobreceria al verse limitado por lo concreto, sino haciendo reales sus virtualidades, algunas de cllas previstas y otras imprevistas en el concilio, y de esa forma enriqueciéndolo. Pero lo transformó recibiéndolo, es decir, dejándose inspirar por lo que realmente dijo el concilio.

Lo recibió también en el sentido eclesial que la recepción de un concilio tenia en los primeros siglos de la Iglesia: con la aprobación del pueblo de Dios. Esta aprobación no se ha dado ahora a través de algún mecanismo jurídico o análogo a él, sino en el mismo hecho de la aprobación masiva de los pobres del continente, manifestada en la esperanza suscitada, en la decisión a vivir sus contenidos, en el sello de inucha sangre martirial. El pueblo de Dios ha dicho "amén" al concilio cuando ha visto a Medellin, como aplaudia en las homilias de Mons. Romero porque se identifica con él. El que la recepción del concilio a I ravés de Medellin haya sido verdaderamente popular es de singular importancia no sólo como hecho hisıórico que mostraria la religiosidad del continente y su capacidad de transformación, sino como hecho estrictam:ente eclesial: el pueblo de Dios ha asumido, ha puesto a producir, ha saltado de gozo con el concilio; en una palabra ha visto al concilio no como algo extrínseco a él, a lo cual hubiera que obedecer aun sin entender, lo cual hubiera que aceptar aun sin convicción, sino como algo propio, algo que ha puesto en palabra lo que consciente $o$ inconscientemente creia y esperaba. Esta recepción popular del concilio a través de Medellín lo convierte en acontecimiento verdaderamente eclesial y no sólo en acontecimiento jerárquico, por necesario y bueno que éste füèse.

Finalmente la recepción del concilio en América Latina tiene el carácter 
del kairos, del momento oportuno y del tiempo de salvación. Visto desde el primer mundo, el concilio, aunque necesaric y bueno, llego con retraso de siglos. El diálogo que entabló con el mundo europeo, con la modernidad, ocurrió para algunos demasiado tarde y no pudo recuperar la le de aquellos que ya se habian apartado de la Iglesia por las posturas antcriores de ésta ante las novedades y las revoluciones de la historia (vèase la revolución lilosófica, cientifica, clemocrálica y social). El mismo concilio tuvo que reconocer que una de las causas del atcismo del mundo moderno estaba en la anterior acunación de la Iglesia. En América Latina no ha sucediclo asi. Ei concilio y Medellin ocurrieron cuando todavia la Iglesia estaba a liempo de introducirse en los necesarios movimientos de libcracion del continenle, de influirlos positivamente clesde su fe, de mantener, por lo tanto, y aun de potenciar la fe de los creyentes que veian necesaria la liberación y sil compromiso con ella.

Por todas estas razones Medellin potenció al concilio recibéndolo pero en esa recepción se dejó orientar por To lundamental de Medellin. A continuación queremos analizar las dos direcciones de esta relación. No lo vamos a hacer de manera histórica y detallada, sino sistemática. Más aún, el "Vaticano II" y "Medellin" fungen aqui como símbolos, como aquello que es lo fundamental de lo ocurrido en y a partir de ambas asambleas, sea cuales fueren sus contexros inmediatos concretos, los procesos y vaivenes de la elaboración de sus textos, las intenciones conscientes de sus autores. Creemcs que el "Vaticano II" y "Medellin" son mucho más que la suma de unos textos. Son una tolalidad compuesta de textos, espiritu y de lo que han desencadenado por su naturaleza. Para analizar esa mutua relación recordaremos lo que en nuestra opinión es lo fundamental del concilio y de Medellin. Dejaremos muchas cosas importantes de lado (ecumenismo, colegialidad, liturgia, etc.) y nos extenderemos en aquello donde más se juega el fuluro de la Iglesia. Por lo tanto, no hay ninguna novedad importante en las páginas que siguen, quizás sólo un recuerdo de lo fundamental para esclarecer lo que en verdad debe evaluar el sinodo.

Huelga decir que al presentar la Iglesia en América Latina se ofrece su realidad ideal consecuente con los principios teológicos en que sc basa. En la realidad, no toda la Iglesia latinoamericana ha recibido de esta forma al concilio y ni siquiera todos los que lo recibieron asi han mantenido esa recepcion. Pero hay también suficientes reaiizaciones históricas de esa Iglesia para que lo que se exponga no sea idealista. En cualquier caso, la parte de la Iglesia latinoamericana fiel al concilio y a Medellin, sigue operando a modo de levadura y se ha impuesto como el criterio más importante para juzgar otras formas de ser Iglesia. Incluso allí donde no está presente, se nota activamente su ausencia. Este tipo de Iglesia, por lo tanto, se ha introducido en la conciencia colectiva del continente como la forma específicamente latinoamericana de ser Iglesia.

\section{La importancia del Vaticano II para la Iglesia latinoamericana}

El Vaticano II, a pesar de la presencia latinoamericana y la importancia, por ejemplo, de las intervenciones de un Helder Camara para encuadrar bien las relaciones de la Iglesia con el mundo y así su identidad y misión, fue un 
concilio fundamentalmente europeo. El contexto, la temática y la teología subyacente estaban muy delerminados por el primer inundo y cn buena medida tambièn para ese primer inundo. Detrás de la universalidad formal de un concilio ecumenico eslaba activamente presente una óptica y un interés concreto.

Sin embargo, por la importancia de lo que sc trató y el espiritu con que se trató, el concilio se abrió a una verdadera universalidad y pudo ser recibido creativamente en América Latina, lo cual no ocurrió, por ejemplo, con el Vaticano I u otros documentos anteríores de la Iglesia universal. Veamos, pues, qué contenidos concretos, entre los muchos que claboró el concilio, se hicieron inmediatamente relevantes para América Latina y por qué.

\section{Los contenidos fundamentales del Vaticano II}

: "Lo más significativo del concilio fue el desarrollo de una nueva eclesiologia Sin embargo, ésıa no hubiese sido posible sin algo lógicamente previo - tanto por razones estrictamente tcológicas como de urgencia histórica-, que posibilitó y exigió tal eclesiología. Recordémoslo, pues a nuestro juicio no se capta sin ello lo más radical que ocurrió en el concilio para América Latina, y la misma eclesiologia conciliar no aparecerá como algo puramente arbitrario o puramente positivista, basado en una lectura, aunque novedosa e importante. de las fuentes redescubiertas.

A eso lógicamente previo a la eclesiologia lo denominamos la recuperación de la creaturidad creyente de la lglesia, es decir, la aceptación de su necesaria y adecuada encarnación en el mundo en cuanto creatura y la aceptación de la permanente necesidad de ponerse ance Dios en cuanto creatura creyente. El concilio no elaboró sistemáticamente esta problemática fundamental, pero da suficientes indicios de su importancia.

El concilio repensó muy a fondo las relaciones entre la Iglesia y el mundo con una finalidad eclesiológica: cómo hacer posible y relevante la misión de la Iglesia. Péro esto lo llevó necesariamente a una problemática pre-eclesiológica, estrictamente creatural y teologal. Por ello, antes de analizar la relación con el mundo recalca la necesidad de encarnación de la Iglesia en el mundo y la retrotrae a su creaturidad. Esto significa en principio la superación de una autocomprensión eclesial autónoma que eficazmente se absolutiza a sí misma como si lo que ocurre en el mundo y en la historia no le afectara en la comprensión teológica de su identidad y de su misión ya supuestamente declaradas $a b$ aeterno. Afirma también que la Iglesia tiene que vivir su creaturidad de una manera específica, encarnada entre los gozos y las esperanzas de los hombres de nuestro tiempo; negativamente, que no puede abdicar de su creaturidad, de participar en aquello en que participa todo ser humano por serlo. Insinúa además, aunque débilmente, que debe vivir su creaturidad de una manera específica y parcial, participando de las esperanzas y tristezas "sobre todo de los pobres y de cuantos sufren' (GS 1). 
Dentro de ese mundo debe realizar su misión, cuyos destinatarios no son sólo los hijos de la lglesia, sino el mundo como tal, "1odos los seres humanos" (GS 2), y cuya finalidad es la salvación en totalidad todo aquel que atañe al ser humano en cuanto tal: "es la persona del hombre lo que hay que salvar. Es la sociedad humana la que hay que renovar. Es, por consiguiente, el hombre, pero el hombre entero, cuerpo y alma, corazón y conciencia, inteligencia y voluntad, quien centrará las explicaciones que van a seguir" (GS 2). Para ello debe reconocer y no presuponer la realidad concreta del mundo, y de ahi que la Goudium el Spes comience con un análisis de la situación del mundo.

Esto supone el fin del triunfalismo y la humildad del aprendizaje, la apercura al mundo para servir, pero también para aprender; en cualquier caso, para dialogar. Se termina con una visión maniquea según la cual la linea divisoria entre el bien y el mal pasaba por la línea divisoria entre Iglesia y mundo. Aunque dicho lodavía muy formalmente y aunque la lglesia deberá concrelarlo desde su especificidad cristiana, lo anterior supone la aceptación humilde, pero también gozosa de su creaturidad y de su responsabilidad hacia la creación. Supone que la Iglesia debe retrotraerse a la humanidad y a la historia y nunca abdicar de ellas, como si su fe la pusiera más allá de ellas, para cncontrar alli el lugar desde donde crecer y desde donde realizar su misión.

La honrada recuperación de la creaturidad lleva también a la primera actitud teologal de la creatura: ponerse ante Dios. La problemática más estrictamente teologal la trató el concilio en la Dei Verbum para dar respuestas a: prob̄lemas teológicos, técnicos, pero en ellas insinúa al menos la adecuada actitud teologal de la creatura.

La revelación de Dios está encomendada a la lglesia (DV 10); sin embargo, ni ella como totalidad ni su magisterio "está por encima de la palabra de Dios, sino a su servicio" (ibid.). La lglesia, además, aunque ya posea el depósito de la revelación, debe seguir siendo creatura, oyente de la palabra de Dios que "sigue hablando sin intermisión con la esposa de su Hijo amado" (DV 8). El Espiritu Santo sigue actuando y "conduce a los creyentes a toda verdad" (ibid.).

El concilio mantiene la dialéctica entre poseer el depósito de la revelación y tener que seguir estando a la escucha de la palabra de Dios. Agraciada con la revelación, la lglesia sigue siendo creatural, sigue teniendo que ponerse ante Dios y hacerlo en la historia concreta actual. Esto se dice de modo eficaz en la Gaudium et Spes al tratar la problemática de los signos de los tiempos. La Iglesia tiene que escrutar, discernir, auscultar lo que ocurre en la historia, aunque ya tenga la revelación. La discusión conciliar sobre este punto fue ardua, sobre todo acerca del significado estrictamente teologal de los signos de los tiempos como manifestación de Dios. Después de varias redacciones, los signos de los tiempos significan aquello que caracteriza a una época (GS 4), en el sentido que les dio Juan XXIII en la Pacem in Terris; tienen un significado 
eclesiológico-pastoral. Pero se explicita también su presupuesto teologal: "los signos verdaderos de la presencia o de los planes de Dios" (GS 11): aqui tienen unn_signifịcado eclesiólogico-teologal. En una palabra, Dios sigue manifestándose en la historia y a través de lo que ocurre en la historia. Esto hay que discernirlo para no adecuar cualquier novedad con la manilestación de Dios, pero hay que discernirlo, pues sin ello no se encuentra a Dios hoy. De esta forma se dice que la Iglesia sigue siendo creatura también al nivel de su relación con Dios, tiene que seguir siendo oyente de su palabra - que deberá ser discernida también desdc la palabra de la revelación-, porque Dios sigue sicndo mayor que ella.

A esta revelación de Dios afirma el concilio que hay que responder con fe. De nuevo el concilio trata aqui de resolver problemas teológicos técnicos en relacion, sobre todo, con lo dicho en el Vaticano l. Pero en lo fundamental afirma que la fe es "obediencia" por la cual "el hombre se entrega todo a Dios" (DV 5). Con ello no sólo se termina con una concepción puramente doctrinaria y unilateralmente intelectualista de la fe como pura aceptación de verdades, sino que retrotrae la fe a lo más prolundamente creatural del hombre: cómo responder y corresponder a Dios en tolalidad, en aceptación de su verdad, pero también depositando en èl la confianza y realizando su voluntad. Y añade, de nuevo en la Gaudium et Spes, la responsabilidad social de la fe, es decir, el influjo de la fe vivida (o no vivida) para la credibilidad de la Iglesia. A los fallos en la fe se debe, en parte, el actual fenómeno del ateismo (GS 19). De esta forma se afirma la dimensión no sólo eclesial de la fe, sino su responsabilidad socio-histórica. Del vivir o no la fe a la manera descrita depende en parte el que los hombres acepten o no a Dios, con el presupuesto de que la fe en Dios humaniza a su creación.

Resumiendo, esta comprensión elicaz de la revelación y de la fe retrotrae a la Iglesia a lo que es estrictamente hablando pre-eclesiológico, a su creaturidad ante Dios. Ese Dios, de cuya revelación es depositaria, sigue siendo mayor que la Iglesia, la hace por definicion oyente de su palabra y le exige una generosa respuesta, más allá de aceptar doctrinariamente su verdad.

En el mundo y ante Dios, desde su creaturidad creyente, el concilio redescubre lo que es la Iglesia como pueblo de Dios al servicio del reino de Dios. Recordemos lo fundamental de la eclesiologia conciliar.

La Iglesia es vista ante todo como sacramento de salvación para el mundo (LG 1-8); a su constitución e identidad interna precede su misión hacia afuera y ésta como salvación. Se torna asi verdaderamente teologal, realizando la voluntad salvadora de Dios para el mundo, poniéndose al servicio del reino de Dios en lugar de hacerse pasar eficazmente por él, del cual sólo es signo.

Esta verdadera revolución eclesiológica de ponerse al servicio del reino de Dios en el mundo y no a la inversa supone la conversión más radical al nivel eclesiológico; exige que la Iglesia se haga mundanal viviendo y actuando en y sobre la historia y exige que deje de ser mundana, no configurándose según los valores del mundo, riqueza, poder, autoritarismo, dominación, Propone, por lo tanto, el criterio según el cual medir el pecado especifico de la lglesia, ade- 
más de los pecados que puedan cometer sus miembros. Y propone el criterio para medir en lo fundamental la santidad de la Iglesia, una lglesia servidora que hace contra su concupiscencia de absolutizarse a si misma y que se deshace en favor de los otros. Propone la identidad de la Iglesia desde su misión como evangelizadora. Ser Iglesia es tener una misión; más aún, es la misión la que irá re-generando a la Iglesia, en el doble sentido del térnino: constiluyéndöla a lo largo de la historia y protegiéndola de su degeneración si su misión es la correcta.

Hacia dentro, la Iglesia es ante todo pueblo de Dios (LG 9-17) con anterioridad a cualquier diferenciación, teológica o luncional, de los diversos carismas y ministerios. Con su ser pueblo se quiere indicar su historicidad, su peregrinaje a través de la historia, stl posibilidad de ientación y fidelidad, su no haber llegado toclavia a la mela. Y se quiere indicar también que las relaciones al interior de cse pueblo sufren una democratización formal, anterior a la diferenciación entre jerarquia y fieles; que deben ser relaciones basadas en la fraternidad; que la legítima autoridad tiene que ejercerse dentro de ese pueblo y según ese ideal, al servicio del pueblo, contando con los aportes del pueblo - Ios más reales, pues es el pueblo como tal el que vive la fe, la esperanza y la caridad-, en diálogo con èl cuando surgen los conflictos. La razón fundamental está en que Dios mismo se manifiesta haciendo una alianza con todo un pueblo, es decir, haciéndolo su correlato inmediato como pueblo; atrayendo hacia a si a ese pueblo percgrino, haciéndose presente en él.

Esta recuperación de la misión e identidad de la Iglesia se justifica en el concilio con los texios de la revelación y de la tradición. Pero el que se haya llegado a ese modo de justificarlas se debe -además de lo que la teología y la vida habian ya preparado- a su honradez crealural antes apuntada. Creemos que esa honradez fundamental es la que posibilita releer también honradamente los textos de la Iradición. La Iglesia del concilio se hizo tradicional, pero verdadera y consecuentemente tradicional; esta es la mayor dificultad para el "Iradicionalismo." Redescubrió el origen más primigenio de la tradición sin ponerlo eficazmente sólo a partir de Trento o del Vaticano 1, sino yendo más atrás de ellos. Redescubrió a los padres de la lglesia y redescubrió sobre todo a Cristo y, en cosas importantes, a Jesús de Nazaret: en él encontró el modelo y norma de su misión, de lo que debe ser la vida de sus discípulos, de los que se congregan en su nombre. La aplicación de la cristología a la eclesiologia, de Torma implicita y más como talante que como método consciente, supuso tambièn una revolución histórica, pues significó argumentar dentro de la eclesiologia no sólo con la tradición y autoconciencia eclesial, sino con la norma non normata de Cristo.

\section{La apropiación del Vaticano 11 por Medellin}

Estas fundamentales verdades fueron r'ecibidas y apropiadas creativamente por la Iglesia en América Latina. Pero es importante analizar por qué, tanto más cuanto que en perspectiva histórica se pueden encontrar muchas limitaciones en el concilio para su apropiación en América Latina: la óptica europea 
de la teologia, el ateismo y no la idolatria como la mayor amenaza a la fe, los análisis hiscórico-políricos insuficientemente radicales, la confianza en el desarrollo, la condena insuficiente del pecado dei mundo, la poca importancia de la Iglesia de los pobres, eic.

Sin embargo, estas limilaciones no impidieron la apropiación. En primer lugar, los contenidos mínimos del concilio supusieron algo verdaderamente importante para coda la Iglesia; dada su fundamentalidad posiliva y lo negativo que querian superar, se impusieron por si mismos. Como minimo el concilio supuso un desbloquen efical de una siluación eclesial insostenible que muchos formulaban, explicila o implicitamente, con las palabras con que Rahner juzgaba por enlonces a la teologia "olicial:" "asi no puede ser." Supuso el lin de una situación insoslenible por el distanciamiento con respecto al presente entre Iglesia y mundo y por ef distanciamiento con respecto al origen entre Iglesia y evangelio. Sujusso una brisa de airc fresco, un volver a poder respirar dentro de la Iglesia en el doble sentido de la metáfora: vivir y sobre todo sobrevivir. Por otra parte, la doble mirada al presente de la historia y al origen normativo del evangelio, y sobre todo la experiencia de que ambas se reforzaban mutuamente, de que era posible hacer coincidir iclentidad y relevancia, otorgaba a las afirmaciones conciliares una credibilidad intrinseca para mostrarlas como verdaderas, no sólo por la autoridad formal de ser textos conciliares, sjno porque sus contenidos rezumaban evidente verdad. La objetividad de los contenidos siempre tiene su propio peso, pero cuando son esperados, consciente o inconscientemente, son realmente bienvenidos. Para el continente latinoamericano, esperanzado y crucificado, esos contenidos minimos se hicieron inmediatamente relevantes.

Pero además de los contenidos, fue también el espiritu del concilio lo que facilitó su recepción. Ese espiritu creó un ambiente de verdadera comunión en las iglesias localcs, desde él sc comprendieron mejor los contenidos. Mencionemos en primer lugar el espiritu de honradez del concilio. Por esta actitud humano-cristiana se llegó a conocer y reconocer la verdad tan sofocada anteriormente por la misma Iglesia: la verdad sobre la verdadera realidad del mundo que comenzó a aparecer cuando la Iglesia lo miró no como una variable dependiente de ella, sino a la inversa, no desde el criterio de lo que el mundo supusiese de apoyo o amenaza a ella, sino desde el servicio que la iglesia prestaba o no prestaba al mundo; la verdad sobre la lglesia misma, su pastoral y liturgia, su teología y sus relaciones internas cuyos impases se hicieron inocultables. El mismo proceder del concilio al rechazar y rehacer los esquemas previos que habían sido entregados a los pobres conciliares dio ejemplo de esa honradez.

Como ejercicio concreto y necesario de esa honradez, el concilio adoptó una actitud de humildad; reconoció el pecado histórico de la Iglesia y que la pecaminosidad le es uno de sus existenciales históricos tan inherentes como la santidad (Rahner) teologicamente no ocurre de forma simétrica, pues ésta pertenece por esencia a su sacramentalidad, pero históricamente el pecado la traspasa. Debido a esta constatación y a una visión más positiva sobre el mundo puso fin, en principio, al triunfalismo eclesial y se abrió al mundo no sólo para 
servir, sino para aprender o al menos para dialogar. Recuperó la humildad creatural y evangélica para hacerse oyente de la palabra sin decidir de antemano dónde y cómo sopla el Espiritu.

Por esa honradez aprendió a releer su propia historia, encontrando su verdadero origen en el evangelio, y juzgando desde sus criterios la tradición, evaluando desde ellos lo que antes habian sido sus mejores (o sus peores) momenlos, según que hubiese tenido riqueza, dominio y poder. Esa honradez le capacitó también para redescubrir la obvia "jerarquia de verdades" (UR 11), lerminando asi con una comprensión de un indilerenciado deposilo de la fe, a rodas luces inadecuada, y olreciendo verdaderos puntos de dircción e inspiración a la fe.

Pero lruto de esa honradez, de la liberación interna que produce la conversión, de la aceptación de su propio pecado - todo lo cual concede ojos nuevos para ver y manos nuevas para actuar-, fue también el espíritu de creatividad y de esperanza. El mismo hecho de realizar ese concilio mostró que el cambio y lo nuevo eran posibles, que el evangelio no es sólo algo que debe ser guardado en depósito, sino algo que hay que poner a producir, que la verdad redescubierta se traduce inmediatamente en nuevas y mejores prácticas eclesiālés. El concilio se encontró con el evangelio en sus manos y eso - y no cualquier voluntarismo o calculismo- generó una gran esperanza. Con humildad, pero sin complejo de inferioridad, podia la Iglesia dirigirse al mundo y ofrecerle una buena noticia. De ahí que el miedo fuese sustituido por el gozo, la tristeza por la esperanza, la apologética a la defensiva por un evangelio que es buena noticia. Todo ello mostro in actu que el concilio fue llevado a cabo y propuesto con espiritu y que desencadenó espíritu, que en el concilio se hizo presente el Espíritu de Dios el cual genera conversión, apertura, vida y esperanza.

Siendo esto asi, se podia esperar a priori que el concilio pudiese ser recibido y bienvenido en América Latina, pues fue un acontecimiento del Espiritu de Dios. Pero también es verdad constatable. Por decirlo gráficamente, en primer lugar, muchos en América Lalina comparlían, con mayor o menor conciencia explícita, el espiritu de Juan XXIII: la humildad para reconocer el pecado de la Iglesia, la exigencia a que abriese süs ventanas para que entrase aire fresco, la utopia de que la lglesia fuese una Iglesia de los pobres, la audacia y esperanza mosträdas en el mismo hecho de convocar un concilio, su fe en úllimo término evangélica por la cual, aun en presencia de problemas sumamente graves, no quería profetas de calamidades, sino anunciadores de una buena noticia. Dicho sistemáticamente, el concilio no sólo propuso contenidos para ser aceptados, sino que fue capaz de crear "el horizonte hermenéulico de comprensión" para ser enlendido y aceplado. Ese espiritu creatural y evangélico fue capaz de hacer salvar la diferencia entre el Vaticano II universal y la América Latina parlicular, retrotrayendo esa diferencia que la hermenéutica debe salvar a la creaturidad creyente y a lo obvio del evangelio en lo cual lodos pueden participar. Además, por ser un concilio pastoral más que doctrinario y, dentro de lo doctrinal, por proponer verdades a realizar, el mismo concilio insinúa de hecho que su comprensión tiene que ir acompañada de su realización. Las inci- 
pientes realizaciones en América Latina mostraron muy pronto la verdad del concilio.

Por todo ello el concilio pudo ser recibido y bienvenido en América Latina. En muy buena medida, sus contenidos y su espiritu ofrecían la capacidad para ser aceptados y puestos a producir. Veamos a continuación cómo de hecho fue recibido el concilio en América Latina. Para ello compararemos sus afirmaciones fundamentales con las de Medellin y Puebla y presentaremos estas como su concreción, no como simple aplicación del concilio. .

\section{La Iglesia de América Lalina como Iglesia de los pobres}

La recepción creativa del concilio tuvo como fruto más significativo la Iglesia de los pobres, apenas entrevista en el Vaticano ll y sancionada por Medellín y Puebla. Pero antes de analizaria, hay que analizar la concreción de lo que hemos llamado presupuestos pre-eclesiológicos.

\section{Exigencias y decisiones pre-eclesiológicas}

La primera concreción del concilio viene exigida por la propia realidad de un continente mayoritariamente pobre y cristiano, lo cual impondrá la dirección a las sucesivas concreciones.

El Vaticano Il menciona muchos y serios problemas del hombre y de los pueblos; algunos de ellos afirmados por los mismos hombres, olros visıs como probiemas desde el punto de vista de la Iglesia, como el secularismo y la increencia. En su presentación, sin embargo, aparece un moderado optimismo sobre las posibilidades del hombre moderno. Medellin sin disinulos, y la ofrece jerarquizadamente, comenzando con el heclıo mayor del continente. Con estas inequivocas y lapidarias palabras cormienza Medellin: "existen muchos estudios sobre la situación del hombre latinoamericano. En todos ellos se describe la miseria que margina a grandes grupos humanos. Esa miseria, como hecho colectivo, es una injusticia que clama al cielo" (Justicia 1), es un verdadero pecado que cristaliza "en las estructuras injustas que caracterizan la situación de América Latina" (Justicia 2). Esa situación injusta, en si misma "conspira contra la paz" ( $\mathrm{Paz} 1)$ y es en si misma "violencia insilucionalizada" (Paz 167).Y Puebla, moderadora de Miedellin en otros puntos, no lo es en éste: "comprobamos como el más devasıador y humillante flagelo la situación de inhumana pobreza en que viven millones de latinaomericanos" (Puebla 29).

En realidad, encubierta durante siglos, ha sido redescubjerta por muchos y también por la lglesia. No está en ella, pues, la mayor novedad del continente. La novedad está en que esa realidad lia Iomado la palabra de forma bien precisa: en forma de un clamor. Por ello Medellin analiza el continente desde su propia realidad objetiva y desde su expresión subjetiva. "Un sordo clamor brota de millones de hombres, pidiendo a sus pastores una liberacion que no les llega por ninguna parte" (Pobreza de la Iglesia 2), a lo que Puebla añade, 
once años después, que ese clamor "es ahora claro, creciente, impetuoso y, en ocasiones, amenazante" (n. 88). Con ser ese clamor novedoso y poderoso no es todavia lo más específico del continente. Después de siglos de resignación, Medellín constata el nacimiento de la esperänza: el clamor es doloroso, pero esperanzado, existe "un anhelo de emancipación tolal, de liberación de toda servidumbre, de maduración personal y de integración colectiva" (Introducción 4).

Esa realidad y esos clamores son realidades históricas, pero también teológicas. Empezar con ellas no significa empezar con preámbulos para la determinación de lo que la Iglesia debe ser y hacer. Es empezar mirando al mundo como lo mira Dios y juzgándolo como lo juzga Dios. Por ello Medellín pone la rcalidad latinoamericana en relación direcia con Dios. En la pobreza infligida injusıamente hay "un rechazo del Señor mismo" (Paz 15); esa pobreza es "contraria al plan del Creador y al honor que se merece" (Puebla 28). Y, por orra parte, los anhelos de liberación son "un evidente signo del Espiritu" (Medellin, Introducción 4). Los pre-ámbulos históricos del ánalisis de la realidad son, pues, también teológicos, más aún, teologales, porque son analizados y juzgados no sólo desde un punto de vista meramente ético o eclesial, sino estrictamente desde Dios. Con esos preámbulos hay que empezar si se quiere en verdad empezar a de-ambular creyentemente y a proporcionar la dirección correcta a ese camino. Lo que Medellin viene a decir es que es en esta historia donde se hace presente la gracia y el pecado, la justicia y la injusticia, el grito de esperanza y los clamores que arrancan a los pueblos sus capataces, la vida y la muerte.

Ese mundo y esos clamores son los que presentan a la Iglesia la primera pregunta teologal, en cuanto creyente, o antropológica, cn cuanto compuesta simplemente de seres humanos: si y en qué Dios cree; o, dicho de manera antropológica; 'și thay algo último por lo que hay que trabajar y qué es eso." Aunque estas pregunias se lanzan también a la lglesia conciliar, en América Latina recobran una fuerza inusitada, una urgencia ineludible y un planteamiento en forma de escalofriante alternativa. Si en el concilio está presente como telón de fondo el ateísmo, en América Latina lo es la idolatria, aunque haya también expresiones de ateismo o agnosticismo convencionales. Muy pronto despućs de Medellín Juan Luis Segundo llamó la atención sobre la antítesis fe-idolatria como la más radical para el creyente, nor ser la más radical para todo ser humano aunque no fuese creyente, en lugar de la antitesis feateismo que se suponia la más fundamental. Con el ateismo, en electo, se puede aprender de él como purificación cle la fe, con él se puede $-y$ según el concilio se debe- dialogar. Con la idolatria ocurre algo muy distinto. Su definición en América Latina viene dada no sólo - aunque esto sea su condición de posibilidad-por la absolutización de lo que no es Dios, sino formalmente por la muerte real que propician los ídolos y por las victimas que necesariamente exigen para subsistir. En presencia de la idolatría real es donde acaece la primera pregunta acerca de Dios: si la Iglesia cree en un Dios de vida y lo muestra propiciándola o si, aun con confesiones ortodoxas, da culto a los idolos generando, por acción u omisión, muerte. La Iglesia tiene que elegir entre la vida y 
la muerte en sus formas bien históricas de pobreza, que genera muerte lenta, pero real, o muerte violenta y represiva. sumo empobrecimienı, a quienes simplemente luchan por vivir.

En este contexto histórico y teologal hay que comprender la concreción que efectúa la Iglesia latinoamericana a la nueva relación entre Iglesia y mundo, aun antes de considerar su misión. Como afirma el concilio, la Iglesia debc ir al mundo; y se ha dicho que esta exigencia supone la mayor novedad de uII concilio desde el primer concilio de Jerusalén en el cual los apósıloles clecidieron 'ir a los gentiles.' Aquella decisión supusn la novedad de sobrepasar ias fronteras del judaísmo en la evangelización con los riesgos y oscuridad que conllevaba. Al 'ir al mundo' ahora la lglesia se adentra en algo todavia más novedoso pues ni siquiera se puede presuponer ya una conlinuidad religiosa, sino una discontinuidad. Pero cuando Medellin exige 'ir a los pobres' expresa otro tipo de novedad en el 'ir.' No hay en ello discontimuidad al nivel de religiosidad, pues los pobres latinoamericanos son creyentes en su inmensa mayoria. Pero hay una radical discontinuidad por el hecho de que son pobres. El ir a ellos implica un ir al verdaderamente otro, quien por el mero hecho de serlo es cuestionamiento radical; implica un ir que es para quedarse, pues sin la encarnación no hay credibilidad, un ir costoso, pues quasi ex opere operato esa encarnación genera persecución, un ir por último en oscuridad porque ante los pobres se percibe que en lo ya sabido de Dios hay mucho de no saber y de no saber fundamental. 'Ir a los pobres' es la concreción latinoamericana del 'ir al mundo' del concilio, verdädera revolución eclesiológica si realmente se va a èllos y no se les hace venir, sutil o burdamente, a donde está la Iglesia. Exige y expresa la primera conversión de la Igesia. "Este acercamiento al mundo de los pobres es lo que entendemos a la vez como encarnación y conversión" (Mons. Romero, Discurso de Lovaina, 2 de febrero de 1980).

Por e! destinatario hacia quien se va, se concreta también la positiva exigencia conciliar del diálogo con el mundo. En el concilio al diálogo presupone que el mundo es distinto y se ha hecho ajerio a la Iglesia, pero que, sin embargo, se debe tratar con él con respeto, sin condenaciones a priori,con la actilud de aprender también de él y con la esperanza de que en el proceso de diálogo pueda haber un mutuo enriquecimiento entre mundo e Iglesia. En América Latina el díblogo de la Iglesia con el mundo toma otra forma, muy distinta. Por una parte la palabra de la lglesia al mundo tiene que ser de dura denuncia y condena al mundo opresor, aunque además se pretenda su conversión. Hacia ese mundo la Iglesia no puede mostrar ni respeto ni comprensión, aunque -y en esto puede haber ayudado el concilio - tampoco to puede hacer con superioridad porque la misma Iglesia durante mucho tiempo ha oprimido a los pobres o ha estado en connivencia con los opresores. Por otro lado, cl diálogo con los pobres no debe llevarse a cabo bajo e! presupuesto de que ellos son ajenos a la Iglesia. No lo son [ácticamente en cuanto son creyentes y viven dentro de la Iglesia; no lo son históricamente porque antes de que la Iglesia hubiese hecho una opción por los pobres, ellos ya habian optado por la Iglesia como tabla de salvación; no lo son axiológicamente, pues por ser un mundo de pobres exige que la İglesia lo haga suyo. Diálogo significa aqui por lo tanto al- 
go distinto. Significa hacerse el otro, empobrecerse, encarnarse de maneı bien precisa. "En este mundo sin rostro humano, sacramento actual del siervo sufriente de Jahvé, ha procurado encarnarse la Iglesia" (Mons. Romero, ibid). Diálogo no es ya sólotespeto y comprensión de los pobres, sino veneración profunda ante quienes presentizan a Cristo crucificado. Aprender de los pobres no significa sólo dejarse purificar la fe, sino dejarse dar lo fundamental de la fe. Llegar a estar en comunión con los pobres no es el último paso del diálogo, sino aquello por lo cual se debe comenzar.

La concreción del diálogo conciliar es, pues, denuncia profética y solidaridad, vivir en el mundo de los pobres, cargar con su pecado y erradicarlo, recibir de su fe y potenciarla. Esto es lo que en sintesis afirmó Medellin: "queremos que la Iglesia en América Latina sea evangelizadora de los pobres y solidaria con ellos (Pobreza de la Iglesia $\mathbf{8}$ ).

De este mundo concreto la lglesia es corresponsable y de su respuesta depende, en parte, el futuro del contincnte y también el futuro de la misma Iglesia. El concilio reconoce que la lglesia ha sido parcialmente responsable del ateismo del primer mundo, el cual la ha fustigado a veces o se ha desentendido de ella. En América Latina la situación es otra, pero más seria. El mundo de los pobres espera la decidida solidaridad de la lglesia. Cuando lä réaliza, lo àradece cordialmente; pero si no la realiza la Iglcsia podrá llegar a escuchar la terrible acusación de la Escritura: "por tu causa se blasferna el nombre de Dios entre las naciones." Lo que históricamente está en juego en la relación de la Iglesia con el continente latinoamericano es lo que clarividentemente afirmó Mons. Romero. "La Iglesia tiene que interpretar y acumpañar a este pueblo que lucha por su liberación o quedará marginada históricamente. Los cambios vendrán con o sin la Iglesia, pero a ella corresponde, por su naturaleza, estar en los cambios que jalonan el reino de Dios" (Cuarta carta pastoral, Misión de la Iglesia en medio de la crisis del país, 6 de agosto de 1979).

La concreción de la relación iglesia/mundo se realiza, por lo tanto, desde lo más Magrante del continente, la pobreza que da muerte, como prolesta contra el pecado opresor y como solidaridad con los oprimidos. Su presupuesto teologal está en la necesidad de la lucha contra la idolatria y en la voluntad del Dios de vida. Citando una vez más a Mons. Romero, "es preciso defender lo minimo que es el máximo don de Dios: la vida."

En ese mundo de pobreza y esperanza la lglesia concrela también dos puntos fundamentales provenicntes del concilio: la revelacion de Dios y la respuesia de la fe.

Para la Iglesia latinoamericana es [undamental y decisiva la convicción de que Dios se sigue manifestando en el presente. De ahi la aceptación de lo que el concilio llama signos de los tiempos, pero sobre todo la importancia que se les olorga como momentos de verdadera manifestación de Dios a los cuales hay que arender con absoluta seriedad si se quiere conocer la realidacl de Dios y sin los cuales no son suficientes estrictamente hablando, aunque sigan siendo absolutamente necesarios, los momentos de revelación de Dios en el pasado. Estos signos se consideran como algo estrictamente teologal y no sólo de impor- 
tancia pastoral, como si la manifestación de Dios a través de ellos empujase si a una acción, pero en los que el previo conocimiento de Dios quedase, por así decirlo, intocado.

Estos signos pueden ser los grandes clamores del pueblo antes mencionados o acontecimientos más concretos como la proliferación de las comunidades, de los movimientos populares, la persecución y el martirio etc; pero lo importante es que a través de ellos se inanifiesta Dios. Y quizás lo más importante y lo más diferenciador --si no con respecto al concilio, sí con respecto a lo sucedido en muchos lugares del mundo en el post-concilio- es la convicción profunda de que Dios habla hoy y que habla palabras concretas, a diferencia de cierto silencio ambiental que se percibe en otras partes y a diferencia tambien de cierta universalización y abstractización de su posible palabra. Y ese énlasis en la posibilidad y realidad del presente de la manifestación de Dios es lo que le convence a la Iglesia latinoamericana de que seguirá hablando en el Futuro, realizando asi in actu una comprensión trinitaria de la revelación de Dios: re-descubrir desde su presente la revelación de Dios en el pasado - plenamente en Jesucristo- y lanzarse hacia el futuro confiadamente en la siempre nueva palabra de Dios que introduce en toda verdad.

En dos puntos concretos ha avanzado la Iglesia latinoamericana sobre el concilió. Él primero es el lugar de la actual manifestación de Dios. La omniprēenencia de Dios no es indiferenciada. Más bien existe una jerarquizada presencia de Dios lo cual llevará a jerarquizar el lugar de su palabra. Puebla insiste en primer lugar en lo concreto de los lugares privilegiados de la presencia de Dios en Jesucristo: en la eucaristia y en la proclamación de su palabra, en quienes se reunen en su nombre y en los pastores enviados; pero añade con clara precisión: "ha querido identificarse con ternura especial con los mts débiles y pobres" (n. 196), citando a Mateo 25 . Si se toman en serio estas palabras se afirma que la omnipresencia de Dios se concreta jerarquizada y parcialmente, y que el lugar de su más densa presencia revelatoria histórica está en los pobres.

Pero además se concreta al concilio en lo que ese lugar del conocimiento de Dios revela de Dios. Puebla dicc que los pobres poseen "un polencial evangelizador" (n. 1147). Por el mero hecho histórico de ser pobres, de cargar con una realidad que les acerca a la muerte, manifiestan la protesta de Dios y desenmascaran cualquier pretensión pecaminosa del hombre de forjarse un Dios según sus intereses. Y si, por otra parte, en ellos y sus sufrimentos está realmente Dios entonces revelan el amor de Dios, en forma de invalidez si se quiere, pero en forma de acercamiento absoluto a lo pobre y pequeño de csle mundo, abajado a los horrores de este mundo, y presentando ese amor al menos -y este 'al menos' es un gran maximo- como creíble.

Pero tambièn manifiestan a Dios por lo que son y hacen, por "los valores evangélicos de servicio, sencillez y disponibilidad para acoger el don de Dios" (ibid.); es decir, se convierten en buena noticia para todos, con lo cual manifiestan a Dios como lo que es en su más profunda esencia, eu-aggelion verdadero. De esta forma los pobres como lugar y contenido de manifestación de 
Dios hacen superar cierta innata tendencia al reduccionisıno doctrinario de la revelación de Dios y la comunican como lo que es anles que nada: comunicación que hace de si mismo el Dios bueno y salvador.

Con esto tocamos fondb en el misterio de la revelacion de Dios, salvifico y escandaloso a la vez. Esta revelación tienc una propia dinámica que culminará cuando Dios sea todo en todos y asi se revele plenamente y como plenitud. Pcro esta totalidad de la revelación no es accesible desde cualquier lugar por igual. Tiene que pasar por la sabiduría de li cruz y sin pasar por ella no se la sobrepasa en la revelación victoriosa de la resurrección. En América Lalina la revelación de Dios pasá necesariamente por los pobres y así cristianiza la plenitud de la revelación. Se vuelve a repetir la escandalosa afirmación de que el siervo doliente es salvación y - lo que más toca a nuestro proposilo ahora-que el siervo doliente es luz (cfr. Is. 42,$6 ; 49,6$ ). Que en la terrible oscuridad del siervo haya luz es inanalizable ulteriormente; pero sólo a través de aquélla se hará cristianamente presente la luz de Dios.

Correlativamente a esa comprensión de la manifesıación de Dios, la lglesia latinoamericana concretiza lo que el concilio afirma de la fe como 'obediencia' y 'entrega de todo el hombre.' La re significa aceptación de la palabra, pero con la dinámica actitud de salir al encuentro de ella (ob-audire), de ser verdaderamente "oyente de la palabra." Pero lodo ello sin ninguna rutina, por la convicción antes mencionada de que la actual palabra de Dios es una posibilidad y una realidad. No hay que responder sólo a la palabra de Dios en el pasado, sino a lo que, en hechos y palabras, sigue manifestando Dios.

Esa obediencia es verdadera entrega y por ello está transida del momento de oscuridad y del momento de plenitud. El momento de oscuridad de la fe, el sacrificium intellectus, aparece con gran radicalidad no tanto por lo que en otros lugares hay de oscuridad teórica, de sacrificio de la razón autónoma, sino porque la entrega se engloba, dicho sin ninguna retórica, en el sacrificium vitoe. La fe se convierte en verdad en la entrega de todo el hombre, entendimiento y voluntad como dice el concilio, y en la posibilidad de la total entrega de la vida. Pero aparece también el momento de plenitud. Si por la le se alcanza a Dios, debe hablarse a priori de tal plenitud; pero la novedad latinoamericana está en la verificación histórica de ese a priori. Esa entrega humaniza, produce más y mejor historia, hace que la esperanza no decaiga, sino que se acreciente, que fomente la caridad, el compromiso y la solidaridad. Históricamente ésta es la verificación de que con la entrega se ha alcan $a$ ado a Dios.

La respuesta de la fe es entrega tolal, por último, desde orro punto de vista. Al Dios que se manifiesta hay que responder y corresponder; hay que responder aceptando, $y$ hay que corresponder haciendo. Aquí está la relación tan recalcada y exigida por la Iglesia latinoamericana de ortodoxia y ortopraxis. La originalidad, no tanto leórica, pero si práctica, está en que ambas cosas son respuestas, dialécticas y complementarias, de una rcalidad primigenia: qué significa 'ser' Iglesia ante la revelación de Dios. Indudablemente significa expresar en palabra correcta su revelación. Pero - por la urgencia de la situación histórica, por supuesto, pero también por el contenido de la revelación de Dios- 
significa una acción exigida por el mismo Dios y que, además, nos va haciendo históricamente connaturales con la realidad de Dios. La ortopraxis viene exigida tan primigeniamente, si no más, por el mismo Dios como la ortodoxia. Como se ha dicho audazmente, "a Dios hay que contemplarlo y practicarlo" (G. Gutiérrez).

En América Latina las preguntas 'quien es Dios' y 'cuál es la voluntad de Dios" aparecen indisolublemente unidas y a ambas hay que dar respuesı. La novedad histórica - por la urgencia de la respuesta práxica y por la menor problemática teórica- está en el énfasis en la ortopraxis. La respuesta teórica sobre la verdad de Dios en si mismo sigue siendo sumamente importante y eficaz para dar mayor aliento también a la ortopraxis y prevenir de sus desviaciones, pero aparece integrada en ésta. Dicho sencillamente, se va conociendo al Dios liberador en la praxis de la liberación, al Dios bueno y misericordioso en la praxis de läbondad y de la misericordia, al Dios escondido y crucificado en cl mantenerse en la persecución y el martirio, al Dios plenificador de la utopia en la praxis de la esperanza. La teologia como infellectus fidei se integra y en último término se subordina al intellecius aınoris, al que lleva a esclarecer y practicar la voluntad salvifica de Dios y asi a conocerle.

\section{La Iglesia de los pobres}

Estos presupuestos pre-eclesiológicos teologales analizados son sumamente importantes para comprender lo que la Iglesia latinoamericana piensa de sí misma en Medellín. Indudablemente en esıa comprensión está la aceptación de la realidad histórica y sociológica del continente; los pobres. Sin la aceptación de esa materialidad histórica no habrá nueva comprensión de la Iglesia. Pero por otra parte, esa materialidad histórica no es aceptada sólo sociológica, sino también teológica y teologalmente. Repetir esto es importante para no concebir lo que va a ser la mayor concreción de concilio sólo sociológica, sino teológica y teologalmente: la Iglesia de los pobres.

Varias veces se levantaron en el concilio, comenzando por la de Juan XXIII, en favor de una Iglesia de los pobres. Desde América Latina don Helder Camara apuntaba a su necesidad con palabras apasionadas. " ¿Vamos a gastar todo nuestro tiempo discutiendo problemas internos de la Iglesia mientras dos tercios de la humanidad pasan hambre? ¿Se quedará sólo el papa Juan en esta lucha? ¿Es el mayor problema de América Latina la escasez de sacerdotes? No. Es el subdesarrollo." Pero incluso al nivel de eclesiologia hubo ruertes reclamos contra los documentos preparatorios que no la mencionaban y elocuentes defensas positivas de ese tipo de Iglesia. Así lo exigió el cardenal Lercaro apasionadamente y Mons. Himmer, obispo de Tournai: Primus locus in Ecclesia pauperibus reservandus est. El concilio no trató el tema, sin embargo, consecuentemente, aunque enumerase algunos principios cristológicos que apuntan a ella: seguimiento de un Cristo pobre y anonadado él mismo, enviado a evangelizar a los pobres y reconocible en los pobres y en los que sufren; $y$ aludiese, aunque genéricamente en exceso, al destino de esa Iglesia: "va peregrinando entre las persecuciones del mundo y los consuelos de Dios" (cfr. LG 8). 
Lo que el Vaticano II clejó sólo esbozaclo es lo que ha clesarrollado la Igle. sia latinoamericana en su comprension linsto ad imra como al extra. Oni es v qué no es esa Iglesia de los pobres, cual es su lundamentu reologico y su litmal, dad, queda claramente expresado en el siguiente párrafo:

La Iglesia de los pobres no es aquella lglesia que, siendo rica y estableciêndose como tal, se preocupa de los pobres; no es aquella lglesia que, eslallldo fuera del mundo de los pobres, les oliece generosamente sll a! udia. Ls,

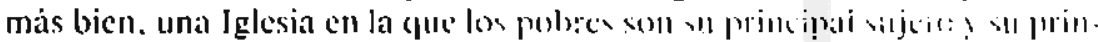

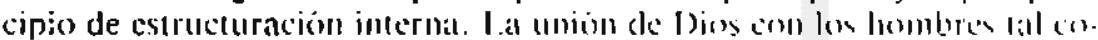
mo se da en Jesucristo es históricamente una union de un Dios aciado en su versión primaria al inundo de los nobres. Asi la lytesia, siendu eila misma pobre, y sobre lodo, dedicandose lundamemalmeme a la salvativill de los pobres, podrá ser lo que es y podra desarrollar iristianamentesu misión de salvación universal. Encarnándosc entre los pobres, dedicando úliamamente su vida a cllos y muriendo por ellos, es el moda cimo pucele constiluirse en signo eficaz de salvación para iolos los hombres (I. Ellacuria) ${ }^{2}$.

\subsection{La misión de una Iglesia de los pobres}

Como en el concilio, la identidad de la Iglesia se concibe en primer ligar desde la misión ad extra, pero con tres concreciones importantes. La primera concreción es establecer el destinatario privilegiado e inmediato dq́la nisión de. la Iglesia: los pobres: Ellos son los que "ponen a la Iglesia latinoamericana ante un desafio y una misión que no puede soslayar y al que debe responder con diligencia y audacia adecuadas a la urgencia de los tiempos" (Medellin, Pobreza 7). Y Pucbla consagra la "opción preferencial por los pobres."

Se da aquí una revolución eclesiológica, sólo insinuada cn el concilio al comienzo de la Gaudium er Spes. Indudablemente la misión de la Iglesia se dirige a todos, pero desde una parcialiclad o prelerencialidacl, si se quicre, la cual la abrirá a la verdadera universalidad cristianamentc entendida. Esıa revolución eclesiológica se exige a la subjetividad de la Iglesia, pues debe hacer una 'opción' novedosa, arriesgada dificil de mantener e históricamence en contra de opciones previas; pero se expresa tambièn en la delerminacion objetiva del destinatario. Los pobres por quienes hay que optar no son simplemente lus hombres comprendidos desde su carencia melalisica, sino los pobres Jisiouricos cuyos rostros describe Puebla sill dejar a cludas (clir. 29-39). Y hay (juc optar por ellos por el hecho primario de que son pobres "cualquiera que sea la situación moral o personal en que se encuentran" (Puebla 1142). Las razones que se aducen para esta revolucionaria opción estan al nitcl pre-cilesiolügico que antes mencionábamos. Teo-lógicamente, "Dios toma su defensa y los ama. Es asi como los pobres son los primeros destinatarios de la mis:ön de Jesús" (ibid.). Cristo-lógicamente, "su evangelización ts por excelencia seìal y prueba de la misión de Jesús" (ibid.). Puebla conoce, exige y alaba otro lipo de pobreza, la "pobreza evangélica" (nn. 1 1485s) para la Iglesia. Pero al deter- 
minar el destinatario de su misión hace una opción preferencial y parcial por los pobres históricos.

Esta deterıninación del destinatario de la misión - histórica y éticamente exigible por la situación del continente- tiene profundas consecuencias para la comprensión teológica de la misión, Ja recuperación de sus origenes biblicos y el modo de llevarla a cabo. Re-descubrir elicazmente el destinatario ha significado re-descubrir también lo que es la misión de la Iglesia. Esıo podria afirmarse a priori dada la correlación enıre misión y destinatario; pero, además. asi ha sucedido. Una misión que cs prelerencialmente para los pobres es concebida como evangelizacion; y éstos son los que han becho redescubrir la esencia de la cvangelización. Esıa es la segunda concreción. 2

Evangelizar es antes que nada anunciar una buena nolicia a los pobres de este mundo tal como aparece en la mnisión histórica de Jesús. De alıj que en la Iglesia latinoamericana sea central - junto con Mateo 25-el texto de Lucas $4,18 \mathrm{ss}$. Lo que se anuncia es el reino de Dios para los pobres, el fin cle sus desventuras, Ta aparición --por fin-del rey justo esperado quien, por serlo, será parcial y hará justicia a los desvalidos; y, por otra parte, la cercania de Dios como Padre al corazón de los pobres y oprimidos, de los despreciados y pecadores según la religiosidad vigente. Evangelizar es, por lo tanto, el anuncio de una gran buena noticia: el amor personal e histórico de Dios a los pobres de este mundo.

De esta comprensión primaria de la evangelización se siguen algunas consecuencias importantcs. En primer lugar la evangelización como anuncio es mucho más que la enunciación de verdades acerca de Dios - aunque las incluya-; es la comunicación de la gran verdad de que Dios es buena noticia. No es, por lo tanto, formalmente enunciar verdades doctrinales, sino comunicàr èl contenido esencial de la gran verdad. De ahi que evangelización será todo aquello que efectivamente, en palabra y hechos, presentice la bondad de Dios para los pobres.

En segundo lugar, evangelizar es concomilantemente denunciar y desenmascarar, anunciar una mala noticia para los responsables de la pobreza injusta de los pobres. Esic aspecto - no muy recalcado en el concilio y ni siquiera en la Evangelii Numiandi, tan imporlante por olros capitulos para la evangelización - vienc exigido por la evangelización porque la buena noticia no se proclama en un horizonte neutro, sino en una realidad hislórica que hace contra la buena noticia. Dios no sólo ama a los pobres, sino que, como dicc Puebla, los deliende. Jesûs no sólo proclama bendiciones hacia los pobres, sino tambièn maldiciones contra los ricos, sus opresores. La denuncia se hace necesaria para esclarecer, por oposición, la buena noticia, para defenderla de los reales ataques contra ella; se luace neccsaria como medio - a veces eficaz, a veces utópico-- para que la buena noticia llegue a ser realidad. Pero la denuncia es también evangelio, buena noticia sub specie contrarii para los opresores. Es la oferta de salvación de parte de Dios si, como Zaqueo, se convierten.

En tercer lugar el anuncio no de cualquier cúmulo de verdades, sino de esta gran verdad que es buena noticia exige una credibilidad especifica en el 
evangelizador. Aunque los pobres esperan aclivamente csa butela noticia, sı realización histórica no es evidente y lo que ocurre en la historia con gran fre. cuencia hace del evangelio un más escándalo que una obviedad. De ahi que cl evangelizador debe estar profundamente convencido de esa buena noticia, que comunique en su propia vida que esa buena noticia es ya en parte una realidad y qute este dispuesto a entregarlo todo, hasta la vida, por ese anuncio. De esta forma, el anuncio no es sólo verdadero, sino crcíble.

La tercera concreción del concilio es el contenido real de ese erangclin al servicio del cual clebe estar la lglesia. El concilio lo prescuta como salvación y la Iglesia latinaomericana lo concretiza como liberación, lo cual fue reiomado por Pablo VI en la Evangelii Nuntiandi. Con el término libcración se sintcliza lo positivo de la salvación y el hecho de que ésta llega a ser a lravés de la negación de la esclavilud.

Tanto Medellín como Puebla afirman claramente que la liberación debc ser integral; total, por lo tanto, y no sólo regional. Negativamente, se dice que debe ser liberación "de lodas las esclavitudes" (Medellin, Inlroducción 4), del pecado personal y social (cfr. Puebla 281). Positivamente, se dice que debe ser "una liberación plena, las riquezas de una salvación integral en Cristo" (Medellin, Catequesis 6); una comunión y participación que establezca nuevas relaciones "sobre tres planos inseparables: la relación del hombre con el mundo, como señor: con las personas, como hermano; y con Dios, como hijo" (Puebla 322).

La indudable novedad histórica de esta visión es la introducción de la salvación histórica en la tarea evangelizadora de la Iglesia. Cómo se compagina ésta con la salvación personal y transcendente es cosa a analizar; pero nada de esta problemática subsecuente le quita necesidad histórica y leológica a la misión liberadora histórica. Las razones teologales ya se han apuntado, y las éticas son evidentes. Añadamos que también de la misma esencia de lo que es evangelización, tal como la presentan Isaias y Lucas, se desprende la necesidad de liberación histórica; pues evangelizar no es sólo anunciar, sino ponerse al servicio del contenido real del anuncio: que la buena noticia se haga buena realidad. Eso lo ha captado muy bien la Iglesia latinoamericana y asi Medellin y Puebla hablān de la tarea liberadora de la Iglesia como defensa de los oprimidos y denuncia de los opresores, como análisis de las causas estructurales de la pobreza, propuestas de una sociedad más justas, cambios radicales de estructuras y la participación de los mismos pobres en la toma de decisiones para configurar su propio destino como pueblo.

Lo que la Iglesia latinoamericana propone es tomar con seriedad y radicalidad los dos momentos de la única comunicación del Dios salvador a los hombres, expresada en la dualidad unificada de 'reino de Dios.' Dios se comunica en su reino constituyendo comunidad, propiciando fraternidad, justicia y amor entre los hombres; de tal manera que si nada de eso ocurriera, vano seria hablar de una comunicación de Dios. Por otra parte, Dios se comunica como Dios, mayor que cualquier concreción de ese reino, polo referencial personal en el cual descansa el corazón y se plenifica el hombre, futuro absoluto y pleni- 
Jicante que alrac hacia si al hombre y a la historia, anima a caminar y construir en la historia. ell medio y a pesar del antirreino presente.

Mantener esa dualidad unificada no cs cosa fácil, pues la tensión puede romperse por cualquicra de los dos polos. Que el énfasis en la salvación histórica pueda recortar o atconar contra lo personal y transcendente es históricamente verosimil; que esto viltimo pueda hacer ignorar o pasar a segundo plano la liberacion histórica es tentación mucho mas real. Lo que la Iglesia latinoantericana hat afirmacto solemenemente es que sim trabajar por la liberación his. corical, vano y ann has licmo veria anunciar colo la Iranscendencia: que esa liberacion historica ofrece ademits un catlec estructural más cristiano que otros para que dentro de el se desarrollen todas las virtualidades de la comunicación de Dins: y ques. por orta parte, la unancendencia de Dios hay que mantenerla por si misma y para humanizar siempre la liberación histórica. Conjugar todos eslos aspecios de la Jiberación es dificil, pero la Iglesia latinoamericana lo ha intentaslo al menos y hal ocurticlo en buena medida.

En último término, aunque no lo hayamos explcitado asi, la misión de la Iglesia latinoamericam se ha concretizado desde la misión de Jesús de Nazaret. Como él hay que anunciar el reino Dios y al Padre, hay que predicar y hacer milagros, hay que bendecir y exorcizar, anunciar y denunciar, arrancar y plantar. En esa vuelta consecuentc a la misión de Jesús y desde los pobres ha concretizado lo que programáticamente afirma el concilio sobre la lglesia como signo y sacramento de salvación.

\subsection{La Iglesia de los pobres como pueblo de Dios}

La definición ad intra de Iglesia que dio el concilio como pueblo de Dios también fuc historicamente revolucionaria. Con ella se contrarrestó una eclesiologia excesivannente orientada hacia cl cuerpo 'místico' de Cristo, la excesiva jerarcología de ese cuerpo, y la tendencia al elitismo de la fe. Con la eclesiologia del pueblo de Dios se devolvió a la base universal de la Iglesia, es decir, a su cotalidad, la primacia sobre cualquiera de sus partes, y se consagró la fraternidad como modelo de relaciones dentro de la lglesia. Como modelo estructural de lglesia ad intra el concilio tendió a una cierra democratización teológica primaria, recalcando el 'todos' del pueblo de Dios, dentro del cual cada miembro de la lglesia aporta diferenciadamente sus carismas y ministerios.

Como ser todo esto de suma importancia, la Iglesia latinoamericana lo concretó desde los pobres. La universalidad del 'todos' se concretó desde la parcialidad de esa totalidad que son los pobres. Estos ocupan un lugar preferencial dentro de la Iglesia no sólo para que la Iglesia se preocupe de ellos -enfoque ético importante-, ni sólo como realidad yuxtapuesta a la de otros que no son pobres -enfoque regional-, sino como centro de la Iglesia y principio desde el cual ésta orienta adecuadamente lo que es y hace, realiza todas sus funciones y ministerios. El pueblo de Dios se convierte entonces en el pueblo 'pobre' de Dios. 
Esta bizarra afirmación tiene en América Lalina una base sociológica indudable, pues la inmensa mayoria de sus miembros sou pobres hisı́cicamente. Pero también su base leológica. Si es verdad la correlación entre Dios y pobres, si el evangelio es primariamentc para ellos, en!onces algo importante c insustituible hay en ellos para la Iglesia y para su constitución, no sólo para su misión. Qué sea eso insustituible vienc dado por el espiritu de las bienaventuranzas. En una lectura sistemática y unificada de las bienaventuranzas según Lucas y según Mateo, el espiritu de Jesís está en los cle corazón limpio - Ios que tienen ojos para ver a Dios-, en los misericordiosos - los que realnente son movidos a amar-, en los perseguidos por la justicia - los que imantienen la fortaleza, la esperamza y el gozo en medio de la persecución por causa de la justicia-. en los que están dispuestos al perdón aun cuando la ofensal es lerrible - la privación lenta y violenta de la vida-, a la reconciliación, a la gratuidad etc., etc. Estos "nobres con espiritu," en la feliz formulación de I. Ellacuria, son el centro inspirador de la Iglesia y por eso las bienaventuranzas, así entendidas, son la carta fundacional de la Iglesia de los pobres. Estos pobres con espiritu son el centro de la Iglesia en cuanto poseen el espiritu cristiano, en cuanto practican la "pobreza evangélica" (cfr. Puebla 1148). Ese espiritu está descripitivamente también en otros miembros de la lglesia que no son pobres históricamente; pero el analogafum princeps de la pobreza evangélica presupone la pobreza también histórica, de modo que esa pobreza ofrece una mayor posibilidad connatural para la pobreza evangélica. Indudablemente no todos los pobres históricos poseen ese espiritu y varios que no lo son lo poseen. Pero estructuralmente hablando, la pobreza histórica es el lugar natural de la pobreza evangélica. Por eso los pobres con espíritu son el centro inspirador y principio estructurados de la Iglesia.

Una Iglesia de los pobres, asi entendida, no excluye a nadie de ella: más bien llama a todos a cooperar en ella. En lo que insiste es en que todos deben relacionarse con ese centro y principio inspirador para que, aun sin ser pobres históricos puedan crecer ellos y hacer crecer a la Iglesia. Con este modelo se Irata, en último lérınino, de recuperar para la Iglesia la antigua noción -que más que una pura noción es un talante de la lglesia calólica- del ex opere operasıo, entendido no mecánicamente, sino como expresión de cauces históricos estructurales de la gracia y de la verdad (cfr. lo que se dice de los sacramentos y del magisterio). La Iglesia de los pobres no es automáticamente portadora de la verdad y de la gracia sólo porque los pobres estan en ella; pero son los pobres con espiritu dentro de ella el lugar estructural para que realmente sea portadora de la gracia y de la verdad.

Quizás pueda ayudar a aclarar este modelo la pregunta de J. Moltmann: "¿En dónde está la verdadera lglesia: en la comunidad manifiesta a través de la palabra y el sacramento o en la fraternidad latente del juez universal oculto en los pobres?" 3 Lo que la Iglesia de los pobres presupone es que esa palabra y esa gracia es don primario a los pobres y a través de ellos a todos; y, por otra parte, que la comunidad que surge alrededor de los pobres tiende a generar comunidad alrededor de la palabra y de la gracia. En cualquier caso es una exigencia histórica, y se verifica ya en buena medida, que la Iglesia no sólo está 
- pues se puede estar en muchos lugares y de muchas maneras -, sino que crece como Iglesia según el evangelio desde los pobres. Asi lo afirma G. Gutiérrez:

En estos años aparece cada vez más claro para muchos cristianos que la Iglesia, si quierc ser licl al Dios de Jesucristo, debe lomar conciencia de ella misma, desde abajo, desde los pobres de cste mundo, las clases explotadas, las razas despreciadas, las culturas marginadas. Dede descender a los intïernos de este mundo y comulgar con la miseria, la injusticia, las luchas y las esperanzas de los condenados de la tierra porque de ellos es el Reino de los cielos. En el fonclo se trata de vivir como Iglesia lo que viven cotidianamentc la mayoria de sus miembros. ${ }^{4}$

Desde este punto de vista hay quc comprender la imporıancia eclesial del fenómeno de las comunidades de base, tan difundidas por América Laina. L. Boff ha analizado en su libro Eclesiogénesis su origen, su realidad, su eclesialidad y su especificidad, y a él nos remitimos. Aqui sólo cabe añadir quc las comunidades de base - sea cual fuerc la ocasión histórica para su surgimiento: escasez de sacerdotes, por ejemplo- son la concreción latinoamericana más especifica del ideal conciliar de devolver importancia a las iglesias locales; son importantes, no especificamente por ser pequeñas y ofrecer asi un ámbito más 'humano' de la Iglesia, más propicio para el mutuo conocimiento y la solidaridad, más propicio a la lectura y apropiación más personal de la Escritura etc., sino fundamentalmente por ser de base, es decir, por estar a la base de la sociedad, en medio de la pobreza, lo cual las distingue de otros modelos de comunidades en el primer mundo; y son importantes, por último, porque desde ellas se engendra la Iglesia, como lo afirma el término 'eclesiogénesis' y lo aclara el subtitulo del libro: las comunidades de base reinventan la lglesia.

Con todo esto se quiere esclarecer lo que significa pueblo de Dios. Al importante avance de「concilio, la Iglesia latinoamericana añade: cl pueblo pobrc de Dios, porque la pobreza es el lugar natural de la Iglesia y porque la pobreza es el lugar desde el cual más connaturalmente surge y crece el espiritu evangélico, la fraternidad y la comunión. Esta parcialidad, una vez más, no atenta contra la universalidad, sino que la potencia; quienes no son pobres sc hacen más evangélicamente miembros de la Iglesia y ésı en su conjunto crece màs y mejor, o al menos más y mejor que cuando se comienza desde la universalidad abstracta de la totalidad del pueblo de Dios.

\subsection{Los frutos de lo Iglesia de los pobres}

La realidad de la Iglesia de los pobres descrita ha generado nuevos frutos en la linea deseada por el concilio. Los pobres como 'principio' han principiado muchas realidades eclesiales. Eniprimer Jugar la unidad intra e intereclesial. Es un hecho innegable que al interior de la Iglesia se ha dado una mayor unidad en el sentido de activa unificación dentro de los pobres y para la misión evangelizadora. Todos los estamentos de la Iglesia, jerarquia, sacerdotes, religiosos y religiosas, agentes de pastoral, catequistas, delegados de la palabrä, fieles campesinos, etc. se han unido en base no sólo a una coordinación intra- 
eclesial impuesta, sino debido a la aceptación de los principios teologales expuestos. También se ha generado una unidad intereclesial, ecuménica, tan deseada por el concilio, en base a los mismos principios.

El modelo formal de esa unidad es ahora el de solidaridad, el de llevarse mutuamente, dando y recibiendo lo mejor que cada uno tiene para la realización de la misión y la construcción, edificación y la Iglesia realización de la misión y la construcción, edificación de la lglesia. Con ello también se propone un nuevo modelo de la catolicidad de la Iglesia; es decir, de la realización de la lgiesia una de las diversas iglesias locales, no ya según el anterior modelo de uniformismo proveniente del centro ni sólo como la yuxtaposición pluralista de las diversas iglcsias locales.

A la base de esa unificación esta la comprensión de la fe, también como solidaridad. La fe concreta de individuos, grupos e Iglesias tienen un elemento personal indelcgable, pero le compete también por esencia estar abierta a la fe de los demas. De esta forma, cntre todos, se corresponde mejor asintóticamente al misterio insondable de Dios. Y de esta forma, al nivel más profundo de la $\mathrm{fe}$, se unifican mejor los individuos y las iglesias. Lo que hay que añadir es que la unidad y la solidaridad se han generado, en la práctica, cuando se ha hecho a los pobres centro inspirador de la lglesia. Ellos ofrecen no sólo su realidad y su fe concreta, sino que éstas tienen capacidad unificadora y enriquecedora. El impresionante movimiento universal de solidaridad que ha generado la lglesia latimoamericana es una prueba palpable de ello.

En segundo lugas la creatividad de la Iglesia de los pobres. En la liturgia ha habido una verdadera traducción no sólo de los textos, sino del sentido de la liturgia en si misma: celebración real de la vida, de la entrega sacrifical, del don de Dios en su palabira y en sus hechos, del gozo de ser cristianos en medio del sufrimiento. En la pastoral y catequeșis han proliferado cursos y publicaciones y sobre todo la formación de los agentes de pastoral, catequistas, delegados de la palabra, responsables de las comunidades; no solo ha habido adaptaciones pastorales, sino uñ cambio en quiénes son responsables de la pastoral. También la pasioral ha acompañado la misión liberadora en la creación de insiiluciones de de fensa de los derechos humanos y en lo que Mons. Romero llamaba pastoral de acompañamiento a los cristianos más comprometidos politicamenıc, donde lo ınás imporıante es la misma idea de acompañar, no sólo de lanzar a los cristianos a esas actividades quedándose la Iglesia a medio camino cuando surgen las dificultades. En el magisterio ha habido una gran creatividad, comenzando por Medellín mismo, y en muchas cartas pastorales de obispos y episcopados - mencionemos sólo a modo de ejemplo las cartas pastorales de los obispos de Brasil y las de Mons. Romero. Ese magisterio ha abordado temas novedosos, dificiles y arriesgados, como la tierra y la transformación agraria, las organizaciones populares, la posibilidad de una legitima insurrección popular, la denuncia de las violaciones de los derechos humanos y el desenmascaramiento de los responsables de la opresión y la represión. Pero los ha abordado también novedosamente, consultando al pueblo de Dios - e integrándolo así en el propio quehacer del magisterio- y tomando en serio sus respuestas, proponiendo los documentos del magisterio 
con autoridad, pero también dialogantemente cuando por la naturaleza y novedad del asumo las afirmaciones del magisterio están abiertas a ulteriores prccisiones y clarificaciones. En teologia se ha desarrollado la teologia de la liberación, cuyo mérito principal es haber mostrado en princípiö $7 \bar{a}$ posibilidad, necesidad y bondad de una teología basada toda ella en Tá Tiberación integral de los pobres; en añadir a la dimensión constatativa y dadora de sentido de la inteligencia su dimensión ético-práxico como esencial también a la inteligencia teológica; en presentar el queliacer teológico como sometido a las caracteristicas de todo quehacer cristiano: disponibilidad a la conversión, servicialidad al pueblo de Dios, disponibilidad a las amenazas y la persccución, apertura a la gratuidad y gozo evangélico en el propio quehacer.

En tercer lugard la persecución y el martirio, a lo cual el concilio sólo alude de pasada (çf. LG B, AdG42). Desde el Vaticano II la Iglesia latinoamericana ha sido la Iglesia que ha producido mas mártires y' los hechos son conocidos. Ha habido centenares y miles de mártires, de cristianos asesinados, la inmensa mayoría de ellos campesinos, pero tambièn religiosos y religiosas, seminaristas, sacerdotes y aun obispos. Muchos otros han sido calumniados, capturados, expulsados, torturados. Muchas plataformas de la Iglesia han sido destruidas físicamente. En su conjunto hay que hablar de una Iglesia mártir en América Latina, aunque hayan sido Brasil, los paises del cono sur y los de Centroamérica los más perseguidos.

La razón histórica fundamental de la persecución es la amenaza que los poderes opresores del comtinente han visto en el tipo de Iglesia que surgió en Medellin. Asi lo dijo explicitamente el informe Rockefeller en 1969, asi ha aparecido en documentos de la CIA y lo han vuelto a repetir los asesores del presidente Reagan. Las oligarquías y ejércitos latinoamericanos han tenido la misma percepción. A esta Iglesia se ha tratado de contrarrestar de diversas formas: con la difusión y financiamiento de sectas que propugnan una religiosidad espiritualista, individualista, no comprometida: con la propiciación de una vuelta a un cristianismo liberal - véase el Instituto para la Religión y la Democracia en Washington-; y lambién con el ataqe directo y la persecucion.

Hay en esla persecución una novedad histórica que la diferencia de las persecuciones en tierras de misiones o en los paises socialistas. Se hace en el mundo occidental, convencionalmente democrático y cristiano, y se justifica implicitamente en nombre de principios cristianos, aunque para ello haya que pervertir la calidad de las victimas, a las que no se las llamará mártires cristianos, sino agentes subversivos y por ello merecedores de su destino.

Ante esta interpretación del martirio, la Iglesia latinoamericana ha defendido en principio la verdad de la persecución. Esta ocurre por dos razones unificadas: por luchar contra la injusticia histórica y por la fe en el Dios de la vida. La Iglesia interpreta la persecución desde la propia persecución a Jesús por su mision denunciadora y liberadora, parcial hacia los pobres y terrible contra los opresores. $Y$ por ello ve también en la persecución y el martirio la verificación de la verdad de la Iglesia de los pobres: le ocurre a ella lo que le ocurrió a Jesús. Aun siendo absolutamente trágico para la Iglesia, y siendo 
dentro de la Iglesia la expresión de un pecado mucho mayor al cual hay que combatir, la opresión y la represión en el continente, la Iglesia, una vez que ocurre, se alegra de la persecucion: "Me alegro, hermanos, de que nuestra Iglesia sea perseguida, precisamente por su opción preferencial por los pobres y por tralar de encarnarse en el interés de los pobres" (Mons. Roinero, Homilia del 15 de julio de 1979). "Una Iglesia que no sufre la persecución, sino que está dislirutando los privilegios y el apoyo de la tierra, esa Iglesia jtenga miedo! No es la verdadera Iglesia de Jesucristo" (Mons. Romero, Homilia del II de mar10 (le 1979).

De esta forma la Iglesia ha propuesto como la santidad lipica suya la sanlidad de Jcsús y la del siervo. La persecución y el martirio son la expresión más inequivoca de que ha habido amor y un gran amor, de que la le no se ha quedado ell palabras y Iormulaciones, sino que ha sido puesia en práctica, de que la esperanza ha sido realmente más fuerte que la muerte.

En cuarto lugar, la credibilidad. Todo lo anterior ha generado para la Iglesia una credibilidad antes desconocida en un continente de pobres y en el cual han surgido numerosos inovimientos de liberación. La persecución sobre lodo ha mostrado la verdad de las nuevas afirmaciones de la Iglesia y de su pastoral; a la Iglesia le ha ocurrido lo que le ocurre al pueblo. Eso ha hecho que el pueblo la sienta realmente cercana y que pueda confiar en ella. Dede ahi hay que entender las terribles, pero clarividentes palabras de Mons. Romero, tantas veces citadas: "seria tristc que en una patria donde se está asesinando tan horrorosamente no contáramos entre las víctimas tambièn a los sacerdotes. Son el teslimonio de una Iglesia encarnada en los problemas del pueblo" (Homilia del 14 de junio de 1979).

Esa credibilidad ha facilitado la aceptación de la acción pastoral de la Iglesia, pero además ha ayudado grandemente al crecimiento de la fe. Entre los pobres la le se ha hecho inucho más madura y se ha mantenido en medio de graves dificultades por que está enraizada liberalmente en la sangre de sus mártires. Entre algunos intelectuales, tendientes al agnosticismo, la fe ha vuelto a cobrar sentido. Entre los no creyentes de tipo revolucionario la fe cristiana es vista ahora al menos con respeto, si es que esta lglesia no tes ha vuelto a acercar a la fe. En cualquier caso esta Iglesia ha logrado algo de suma importancia pensando sobre todo en la actual y previsible situación de movimientos liberadores que se presentan como salvílicos. De la fe cristiana no sc puede decir ya impunemente que, en las conocidas palabras de Marx, es opio para el pueblo, ni que, en palabras de la Escritura, "por un causa se blasfema el nombre de Dios entre las naciones."

Por último, la larimoamericanización del evangelio y la evangelización de América Latina. Con esto queremos decir que evangelio y continente latinoamericano se remiten ahora no como instancias ajenas la una a la otra a las cuales haya que intentar unir voluntariamente, sino cono lo que mutuamente se polencia, salvada siempre la gratuidad con que se comunica el evangelio. El evangelio de Jesús y la Escritura toda han ayudado a descubrir y comprender mejor la realidad latinoamericana, su tragedia, su esperanza y la dirección de 
la liberación. América Latina, por su parte, ha ayudado a re-descubrir lo que estaba siempre en cl evangelio y en la Escritura, a descubrirlo eficazmente según un determinado modo de lectura: como comunidad y dentro de la realidad histórica. Ha ayudado también a re-leer la propia historia de la Iglesia latiñoamericana y a interpretarla y evaluarla más cristianamente. Asi se valora hoy de muy dislinta forma el sustrato religioso de las civilizaciones precolombinas, la actuación de los obispos como defensores ex officio del indigena. Con ello se logra una concepción propia dél evangelio y de la historia cclesial.

Estc heclos es de capital importancia. Los creyentes latinoamericanos no sienten ya que su relación con cl crangelio les viene mediada en principio por algo ajeno a cllos. Evidentemente existen las mediaciones históricas, los inisioneros, las teologías que históricamente han venido de fuera; pero éslas no sön ya mediaciones estrictamente necesarias en principio. El evangelio habla directamente a los pobres del conlinente y cllos lo consideran como suyo No. significa esto ni desprecio hacia lo que otros of recen de evangelio, pues ya heimos mencionado el modelo de solidaridad en las relaciones intraeclesiales, ni complejo de superioridad ni desconocer las instancias normativas de la autotoridad central de la Iglesia. Lo que significa positivamente es que cl continente latinoamericano no necesila dar un rodeo a través del primer mundo para llegar a su autoconcicncia cristiana en lo fundamental de ésta. En un sentido siempre ha sido asi, pucs la religiosidad popular ha sido creación de los pobres del continente; pcro ahora se recalca más. El evangelio de Jesús habla directamente a los pobres del continente latinoamericano.

La latinoamericanización del evangelio implica hacerlo históricamente latinoamericano y no otra cosa. Pero no implica la desaparición de la alteridad del evangelio con respecto a América Latina, antes al contrario. Lo que ha ocurrido es que csa alteridad es comprendida a su verdadero nivel: no al nivel geográfico, sino a! nivel de la gratuidad del evangclio, del evangelio como don; al nivel teologal, por lo tanto, y no al nivel de las mediaciones de trasmisión del evangelio. En América Latina el evangelio es captado como don y, por último, como lo que es: eu-aggelion, buena noticia. Los pobres del continente, y de todo el mundo, son el lugar de mantener esa clemental verdad. La latinoamericanización del evangelio,por hacerse en un continentc de pobres, la ayudado a devolver al evangelio su sentido más original. Y éste no es pequeño fruto de una Iglesia de los pobres.

\section{Evaluación de la Iglesia de los pobres}

\section{La Iglesia de los pobres ante el sínodo}

Esta Iglesia de los pobres es una realidad en América Lalina. Cuantitativamente está en todo el continente, aunque de forma desigual, más extendida en unas parles que en olras. Pero está sobre todo cualitalivamente, en forma de levadura que fermenta la masa, no como secla cerrada en medio de la tolalidad de la lglesia ni como diáspora resignada de unos nocos. Lo que habrá que evaluar es sobre todo su calidad, su capacidad de of recerse como modelo inspi- 
rador a loda la Iglesia, su necesidad para cl presente y futuro de América Latina.

Al evaluarla hay que tener en cuenta ante todo su profunda novedad posiira. G. Gutiérrez ha afirmado que la historia de la Iglesia en América Lalina se divide en antes y después de Monseñor Ronsero. Con este simbolismo se quiere afirmar el profundo quicbre que ha ocurrido en la Iglesia en los úlimos anos. Fstamos ante una novedad de gran suvergadura $y$ de incalculables consecuencias. Esta profunda novedad y su significado es lo que antes que nada tiene que evaluar el sinodo, scin cuales lueren las cvaluaciones de sus aspectos parciales.

La Iglesia latinoamericana ha aparecido, por lïn, con un carisma propio calpaz de englobar toda la vida cristiana de forma nucva. No ha sido la aparición sólo de una nueva doctrina o de una nueva eclesiologia, sino de un carisma que ha comado cuerpo hisiórico, se ha convertido en luente de identidad, en marco refercucial y en norte para el luturo. Esc carisma se ha mostrado con la suficiente fuerza como para reorganizar todo lo eclesial, fe, misión, organización interna. $Y$ ese carisma ha creado ya tradición, de modo que los cristianos son conscientes de lo que han recibido y de lo que deben entregar.

El quiebre histórico es por lo tanto muy profundo. No es un quiebre simplemente para abandonar un pasado, sino para rehacer el presente; no es para perder sustancia eclesial - por desinterés, rechazo o simple desvinculación eclesiales - sino para ganarla de forma adecuada. En este sentido es el tipo de quiebre que aparece periódicamente en la historia de la Iglesia, como lo fueron las dos reformas o la fundación de órdenes religiosas reformadoras los movimientos populares evangélicos o los obispos de la colonia defensores ex officio del indigena.

Este quiebre es necesario -como ocurre en las épocas de la historia en las que se espera un profeta que supere lo antiguo-y es positivo - como cuando el profeta que llega sabe responder a la esperanza. Todas las páginas anteriores han pretendido mostrar ese quiebre en lo que tiene de novedoso y de positivo. Resumámoslöbrevemente diciendo que este quiebre ha supuesto ante lodo una nueva apropiación del evangelio de Jesús, análogo -aunque sin caer en anacronismos históricos y teológicos - a la apropiación de Jesús por parte de las diversas comunidades del Nuevo Testamento, las cuales veían a Jesús relacionado con lo concreto de ellas, con su concreta necesidad de salvación, con su carácter de buena noticia para ellas, y que se remitían todas a Jesús, a pesar de sus diferencias, para confesar que la verdadera buena noticia es la que él trae. El quicbre está en que América Latina está rehaciendo el evangelio, sin manipularlo, pues se remite a Jesús -y si no hubiera otra prueba de que no hay manipulación en principio bastaría apuntar a los mártires, testimonio de que es el evangelio de Jesús y no cualquier evangelio interesado el que se ha recibido-, pero concretándolo desde la comunidad. El quiebre está en que esa Iglesia de pobres puede escuchar mejor a Jesús, seguirle más de cerca y parecerse más a él.

El quiebre ha supuesto que la Iglesia ha encontrado su lugar en la historia 
y con ello resuelve en principio el grave problema de ser del mundo y no serlo, de la adecuada relación entre transcendencia c historia. Una chcarnación de la Iglesia que no sea en el mundo de los pobres la lleva hisióricamente a hacerse mundana -en el sentido pecaminoso del término-, a adoptar consciente o inconscientemente los valores y actitudes del mundo, la comprensión y cl uso del poder sobre todo descle la comprensión y uso que hacen de el los nocleres cle este mundo. Este tipo de encarnación no hace de la historia lugar de la transcendencia, la cual tendrá que ser doctrinariamente mantenida, pero paralelanente a la historia, sin convergencia con ella y, muchas veces, contra clla, negando con la historia lo que se afirma con la transcendencia. Encarnada en el mundo de los pobres, sin embargo, la lglesia se hace mundanal -en el sentido positivo del lérmino: lo que toma carne y carne débil como el Hijo--, y esı le permite encontrar la Iranscendencia en la historia sin paralelismos y. en principio, sin reduccionismos. La pobreza - como aparece en la profunda intuición de San Ignacio- tiende a generar los "oprobios y menosprecios" y de ahi todas las virtudes. La pobreza es el lugar desde el cual la historia crece cristianamente y puede ser puesta en relación con la transcendencia de Dios. El olro mundo, el de la riqueza, no hace crecr en la dirección de la salvación, sino del pecado; y por ello no es el lugar de la transcendencia. Ser verdadera y no sólo intencionalmente mundanal sin ser mundana es la tarea de siempre de la Iglesia, muchas veces mal resuelta. A este grave problema ha dado solución la Iglesia de los pobres.

Este quiebre ha supuesto por último quc la lglesia puede ser respuesta a los problemas del continente, puede ser sacramento de salvación. la Iglesia ofrece siempre la salvación de Dios, pero a su vez debe concretarla desde las formas concretas de condenación. No cualquier forma de ser Iglesia puede responder a cualquier necesidad de salvación. Sólo una Iglesia de los pobres puede salvar en un continente pobre. Pero además - a diferencia de lo que ha ocurrido muy frecuentemente en la historia- esta Iglesia puede dar respuesta a los movimientos de liberación, reconociendo y apoyando - además de aprender de ellos- la necesidad y justicia de su causa, y tambièn potenciándolos y sanándolos. Hay aqui una profunda novedad; Iglesia y liberación no aparecen como divergentes o contrarias: la lglesia aparece en favor de la historia y no contra ella. Una Iglesia de los pobres puede hacerlo y puede incluso evangelizar los movimientos de liberación para que éstos sean más cristianos o recojan al menos lo humano y humanizador de la fe; pero todo ello lo puede hacer en último término porque tiene credibilidad. Por decirlo claramente, la Iglesia de los pobres y sólo ella es la respuesta eclesial al reto de las revoluciones, asi como la teología de la liberación es la respuesta teológica al reto del marxismo. Esto es lo queremos afirmar con la profunda novedad positiva y esto es ante todo to que se debe evaluar y discernir.

Dicho esto, hay que analizar también la problemática de esa Iglesia, evaluar sus realizaciones concretas. Pero hay que ser conscientes desde el principio de qué criterios se usan para el análisis, si criterios objetivos o criterios ya ideologizados desde los cuales se ha decidido de antemano contra ella. Esto último es lo que ocurre en la actualidad al denominar a la Iglesia de los pobres 
como "Iglesia popular" la cual, por defunición, seria antijerárquica y de inspiración marxista. En su conjunto creemos que esto es más una excusa que una razon para clesciuliticarla. Para poder hacerlo ha l:abido que exagerar y confundir lo que es énfasis con reduccionismo mutilante de la fe, lo que es profecia con ataque desleal a la Iglesia, lo que es análisis con lo que es ideologia. La Iglesia de los pobres tienc lambién su problemática pero hay que analizar suidadosamente en qué consiste.

En primer lugar. el mayor problema de la Iglesia de Ios pobres es ella misma. La radicalidad del evingelio en que se inspira y quiere presenti/ar es suma. mente exigentc y por ello uada fácil de mantener. Cuando arrecia la persecución, adsmás, esa Iglesia se ve diezmada, amenazada en sus personas y plataformas; no todos pueden mantener el ideal de esa Iglesia en esal siluación y es comprensible el movimiento a abandonar esos icleales. Por la altura del ideal es comprensible que haya fallos en esa Iglesia.

La Iglesia de los pobres, además, sigue siendo crealural, limilada, concupiscente y amenazada de pecaminosidad. En un fenómeno de tal magnitud y con el existencial histórico de la pecaminosidad no se puede negar que ha habido exageraciones y unilateralidades y en algunos casos hasta abandono de la fe o al menos de su expresión eclesial. El necesario y urgente énfasis en la liberción histórica lıa podido hacer pasar a segundo plano los aspectos personales y transcendentes de la fe. Como toda Iglesia, tiende a ser manipulada por otras fuerzas sociales, económicas y políticas, en este caso desde la izquierda, y ha habido en ocasiones excesiva subordinación a ellas.

Todos éstos son problemas reales. Lo que hay que hacer es cuantificarlos, analizar si los fallos opacan en lo fundamental lo positivo de la Iglesia de los pobres o no, si son incoherencias inevitables o consecuencias necesarias; analizar en último término si la Iglesia de los pobres es una utopia inviable o si sigue siendo una posibilidad a pesar de sus limitaciones. En nuestra opinión, sigue siendo viable y necesaria; el mismo reconocimiento de estos problemas por parte de sus miembros, los es fuerzos por superarlos y las realidades positivas que siguen generando hacen que los fallos no atenten contra lo fundamental.

En segundo lugar hay que analizar la problemática que ocasiona la Iglesia de los pobres a la totalidad de la Iglesia precisamente por serlo. Si el evangelio es la mayor fuente de problemas para la lglesia, también lo será, aunque en Corma más mitigada, la lglesia de los pobres.

La Iglesia de los pobres unilica, pero también divide. No lo pretende ciertamente, pero al presentizar con claridad el evangelio de Jesús y la siluación escandalosa del continente se convierte en signo ante el cual se dividen los espiritus. Esa Iglesia toma muy en serio el encarnarse en, cargar con y erradicar el pecado del mundo. Como la ioma de postura ante ese pecado, ante lo que sea el mayor y más grave pecado y ante lo que hay que hacer con él es desgraciadamente diversa y muchas veces opuesta, entonces la división se introduce en la lglesia y con una radicalidad mayor que la que origina la diferencia entre jerarquía y lieles, la diversidad de escuelas teológicas o la diferencia de confesiones cristianas. Lo que divide realmente a la Iglesia en su interior 
es la respuesta a la pregunta del mismo Dios, que has hecho de lu hermano; y por ello la división es grave e inocultable.

La Iglesia de los pobres, por lo tanto, no sólo tiene sus propios problemas, sino que los causa y tanto mayores cuanto inás fiel es a su identiticlad evangélica y latinoamericana. Si a la división seìalacla se àiacle la persecución que origina, la novedad en el modo ile proceder ante los grankies de este mulido, el no saber qué pensar y qué hacer en un primé momento déluru del mundo de los pobres, sc comprenderá yue esta forma de ser Iglesia es realmente problematizante. I.o clue no se debe iacer, al evaluarlat, es conlundir lo problemático de ella por ser limitada con to problematiıante cle ella por ser evanġlica.

En tercer lugar hay que analizar las diliculıades que la Iglesia universal pone a la Iglesia de los pobres. No se puede dudar de que la Iglesia en general está pasando por un momento de involıción que algunos llegan a calificar de vuelıa al integrismo. Esta involución a fecia muy específicamente a la Iglesia cle los pobres en cosas muy importantes de ella. Esta involución se nota en el resurgir del interés primario de la Iglesia por si misma, aunque se arguya que es para mejor servir al mundo, frente a la centralidad de su mision; cn el resurgir del centralismo y autoritarismo frente al estilo [raternal y dialogante; en la búsqueda de control y de seguridad administrativa - véase los nombramientos de nuevos obispos en América Latina-y doctrinal -véase la formación en muchos seminarios, el juicio sobre la teologia de la liberación-; cn cl exagerado triunfalismo eclesial al juzgar de los males del contienente y sus causas -capitalismo y, sobre todo marxismo- sin reconoer la responsabilidad de la Iglesia en ellos por acción u omisión; en la tendencia a la pura ortodoxia, incluso a la avanzada ortodoxia en cuestiones sociales y de derechos humanos, pero sin una práctica consecuente y proporcionada; en la ideologización de los juicios sobre la realidad histórica - el mayor de los malcs seria el marxismode modo que en último término no peligre el mundo occidental, convencionalmente democrático y cristiano. Ante esta involución, la Iglesia de los pobres quiere mantener la revolución de Medellín, pero ahora se encuentra estructuralmente tensionada.

Una evaluación honrada de la problemálica de la Iglesia de los pobres debe tener por lo tanto en cuenta lodos los aspectos de ella: lo que ella misma tiene de problemática por ser creatural, lo que tiene de problematizante por ser evangélica y también el proceso de involución que la presenta problematizada.

Hay que evaluar por último la reacción de la Iglesia de los pobres ante esta problemática. Lo primero que hay que afirmar es que esa Iglesia sigue en la historia, está pasando la prueba del tiempo y de esa forma se está 'institucionalizando,' está creando una tradición enraizada en la historia. Al nivel de manjfestaciones externas, no pasa ahora por los momentos de brillantez como lo fueron Medellín o las cartas pastorales de los obispos brasileños o de Mons. Romero, pero sigue con mayor sobriedad y mayor mérito, pasados los primeros momentos de entusiasmo y pasada la prueba de la persecución.

Esta Iglesia, a pesar de ser cuestionada, se mantiene dentro de la estructu- 
ra jerárquica de la lglesia. No hay ningún indicio de que quisiera convertirse en Iglesia cismática, como afirman algunos. Activamente busca el diálogo con la jerarquia porque se siente lglesia, apoya -cosa que no hacen otros miembros de la Iglesia - todo aquello que haga la jerarquia y suponga algún riesgo contra ella de parte de los poderosos, sc alegra de la fraternidad intraeclesial cuando se da y trabaja por ella. Pasivamente, acepta con espiritu creyente las disposiciones de la jerarquía aunque seall clolorosas, sabe guardar silencio, sabe obedecer en lo fundamental. 'Todo esto esta presente incluso en ei caso de Nicaragua, aunque alli la tensión paresca insuperable; pero uno de los grandes anhelos es poder llegar a estar en verdadera comunión, en diálogo al menos con la jerarquia, expresión minima, si se quiere, pero real de eclesialidad.

Esıa Iglesia por último está pasando la prueba más dificil que es ella misma y sus exigencias. Esta lglesia la madurado antes de que se lo pidiesen sus opositores. Asi, manteniendo la siempre urgente necesidad de compromiso histórico con la liberación, ha crecido en la dimensión personal y iranscendente de la fe; su teología ha ido desarrollando una visión de Dios como liberador y también como Padre, una visión de Jesús como portador de la buena noticia del reino y tambièn como el Cristo que es en sí mismo buena noticia, una espiritualidad que es vista como necesaria y, en el fondo, como lo más auténtico de esa Iglesia, espiritualidad que surge de y acompaña el caminar de esa Iglesia. Manteniendo la necesaria presencia de los cristianos en los procesos de liberación, ha crecido en la comprensión de lo que debe ser el aporte cristiano a ellos: la defensa de su justicia, legitimidad y necesidad, pero también la necesidad de imbuirlos de espíritu cristiano, humanizarlos, desdogmatizarlos tanto desde el punto de vista ideológico como desde la conducción realista de ellos. Esta Iglesia reconoce sus propios fallos y está dispucsta a la conversión; es una Iglesia que sabe tambièn perdonar, muchas veces en situaciones heroicas, y está dispuesta a la reconciliación. Por todo ello, aun con sus limitaciones y pecados, la Iglesia de los pobres sigue siendo una realidad viva, está superando la problemática que la rodea, ha llegado a la hisıoria para quedarse.

\section{El sinodo ante la Iglesia de los pobres}

Esta Iglesia es la que se pone ante el sinodo para ser evaluada. Ojalá el sínodo sepa captar su realidad, sobre todo la positiva novedad que hemos descrito. Pero esta Iglesia también of rece al sinodo sus mejores frutos con una petición y una pregunta.

La petición es que el sinodo actúe con la crealuridad creyentc con que actuó el Vaticano 1l, con honradez fundamental ante el mundo y ante Dios, con esperanza y confianza, con apertura y creatividad, que con esas actitudes mire al mundo de hoy en primer lugar y al tercer mundo crucificado para determinar desde ahi su misión y la concreción de la salvación.

La pregunta es qué otro tipo de lglesia que no sea la Iglesia de los pobres puede ser hoy fiel a Jesús y relevante para el mundo. La Iglesia de los pobres es cada vez más una necesidad. Lo es para la realidad histórica del continente latinoamericano, pues la lglesia puede y en algunos aspectos sólo ella puede dar 
una esperanza y orientación al caminar liberador de los pobres; y si puede hacerlo, debe hacerlo por honradez. fundamental hacia Dios y hacia los pobres. Lo ès para la fe, pues sólo ella puede testimoniar la fe en un Dios de vida y la re en un Cristo salvador; sólo ella puede seguir leyendo el evangclio con ojos de pobre y seguir así siendo la Iğlesia de Jesús. Pero lo es también para la misma Iglesia, pues sólo una Iglesia de los pobres posec la suficiente credibilidad para seguir activa e influyente en la sociedad. Cn esio la lglesia debe esiar clara y no confundir triunfos inmediatos con la batalla de los siglos futuros. EI decaimiento de la Iglesia y de la fe en muchos otros lugares del mundo la debe hacer reflexionar sobre si el mejor modo de evilar algo sennejante en América Latina - continente mayoritariamente cristiano y en el que se concenirarán la mitad de los católicos en poco tiempo-es pretender un orden y anibiente cristianos con el necesario apoyo de los poderes de este mundo o proseguir el camino evangélico propuesto por el concilio y Medellín. Una lglesia de los pobres que se encarne entre sus sufrimientos y esperanzas, que acompañc sus procesos de liberación impulsándolos y purificándolos, que se entregue a ellos y dé su vida por ellos es lo que humanamente garantiza a la larga el futuro de la Iglesia; quizás incluso su supcrvivencia, pero en cualquier caso su vivencia como Iglesia de Jesús.

Esa Iglesia de los pobres surgida de Medellin es lo que la lglesia latinoamericana devuelve a la Iglesia universal. No trata de imponer nada a nadie, pero se ofrece como ayuda a otras iglesias y a la Iglesia universal. Muchos, aun en los actuales tiempos de involución, encuentran en esa Iglesia la esperanza para toda la Iglesia.

El Vaticano II ayudó mucho a que surgiese esa lglesia de los pobres; ahora ésta quiere prestar una ayuda al sínodo universal. Lo primero significó la recepción del concilio por la Iglesia local latinoamericana; lo segundo debiera significar la recepción por parte del sínodo universal de lo que ha producido, junto con otras, una Iglesia local. Si esto ocurre, se habrá encontrado un verdadero modelo de catolicidad. En cualquier caso, ésta es la expectativa de la Iglesia de los pobres y de los pobres de este mundo.

\section{NOTAS}

1. Este articulo es la reelaboracion del escrito "El Vaticano II y la Iglesia en América Latina" que aparecerá en el libro Concilio Vaticano II: veinte ahos después publicado por Ediciones Cristiandad. La reelaboración se ha hecho ieniendo en cuenta la proximidad del sinodo.

2. Conversión de la Iglesia al Reino de Dios, Santander: Sal Terrac, 1985. p. 270s.

3. La Iglesia, fuerza del Espiritu, Salamania: Sigucme, 1978, p. 160.

4. Teologia desde el reverso de ta historia, Lima: CEP, 1977, p. 154. 